\title{
STUDENT COACHING FOR RETENTION IN A DISTANCE LEARNING ENVIRONMENT
}

\author{
Tamar Benaya (tamar@cs.openu.ac.i1) \\ Ela Zur (ela@cs.openu.ac.i1) \\ The Open University of Israel
}

\begin{abstract}
The Open University of Israel (OUI) is a higher education institution with an open admission policy which is based solely on distance learning and self-study. The teaching method practiced at the OUI is a combination of traditional and web-based distance learning. One of the issues of great concern in all institutions and even to a greater extent in open and distance learning institutions is student retention. In an attempt to deal with this problem, the OUI decided to embark on a Retention Project which aim is to help new students to overcome the hardships of the first course. The new students were offered to be paired up with senior students who would accompany and coach them throughout their first semesters. This paper describes the Retention Project, and it presents results concerning the performance of the coached students, their retention at the OUI and the means of communication used by the coached students and their coaches in a distance learning environment.
\end{abstract}

Keywords: distance learning, higher education, means of communication, open university, student retention.

There are many universities all over the world that offer distance education programs for off campus students in addition to their face to face mode of education. The Open University of Israel (OUI) is a higher education institution with open admission which is based solely on distance education. This combination of universities which are both open and based primarily on distance education is not very common. A thorough description of such universities can be found in Guri-Rosenblits (1999). The OUI offers a variety of undergraduate programs and several graduate programs. A detailed description of the different undergraduate and graduate programs can be found in the OUI Website (http://www.e-openu.ac.ie).

The OUI is similar to other universities in its pursuit of excellence and its commitment to superior scientific and scholastic standards. However, it differs in that it is open to all those who wish to study towards a Bachelor's degree. Enrollment does not require matriculation or any other achievement exam or certificate from another educational institution. Though applicants are not required to provide proofs of prior scholastic achievements, their academic achievements are the key to their successes at the OUI. In contrast to the open admissions policy for undergraduate studies, admission to graduate studies in contingent on fulfillment of certain requirements (Benaya \& Zur, 2007).

The teaching method practiced at the OUI combine two modes of distance education: written materials which are sent to the students at their homes and web-based teaching. In the past 
decade, the OUI supplemented its traditional distance education with course websites since the demand for educational web-based learning is increasing in distance education learning communities (Gal-Ezer \& Lupo, 2002). Both modes of education are based on many years of experience practiced at the OUI.

The various aspects of distance education developed by the OUI, along with the university's open admission policy, aim to open the world of higher education to all, irrespective of age, sex, place of residence or occupation, in order to enable even individual to realize his or her academic ability. The distance education practiced at the OUI enables students located throughout the country, to pursue their higher education without leaving their home towns.

The course material is based on books especially adapted to self-study. Each course includes a face-to-face component in the form of small group tutorials led by a tutor. However, this component does not constitute the core of the course. Students who wish to turn their home into a personal campus can do so due to the distance learning method practiced in the OUI. The tutorial sessions are held at the OUI study centers dispersed throughout the country.

Students must submit assignments, exercises or other types of tasks during the semester. The assignments are submitted by mail or via the Internet. Students receive a grade and feedback on each assignment and they must also pass a final examination held at study centers near their homes.

Each course has a course coordinator who is responsible for the academic and administrative planning and the implementation of all course activities, including the web-based ones (described below). The coordinators and tutors are those who provide the contact between the student and the OUI. Students may consult with coordinators and tutors concerning any question which troubles them-academic or administrative. The course staff accompanying the students throughout the courses is attentive to their problems and does its best to solve them.

The OUI also makes use of web-based technologies to improve its distance teaching, which provide a wealth of learning materials and continuous contact with faculty and other students in the course. All the courses in the OUI have course website on the internet which provides an interactive learning environment. The websites include many interactive learning and administrative elements such as follows. (a) A discussion group where the students post questions and comments regarding the course material. On many occasions the students respond to each others questions and the discussion takes place. The course tutors and coordinator follow and contribute to these discussions. (b) Supplementary learning materials such as tutorial lecture notes, links to additional material and to data-sources on the internet, exercises and sample exams. (c) Course bulletin board used mostly by the course coordinator for announcing schedule changes, important notices and special events. (d) List of fellow students which facilitate contact and collaboration among students in the course. (e) Several administration tools, such as an online assignment submission system. 


\section{THE RETENTION PROJECT}

Student retention is clearly an issue of concern in all institutions of higher learning and even to a greater extent in open and distance institutions (Tresman, 2002). There are many factors which influence retention, some of the major ones are: the quality of students' experiences (Martinez, 1997), students' exceeding their personal threshold and difficulties integrating studies with personal life (Tresman, 2001). Peterson, Kovel-Jarboe, \& Schwartz (1997) claim that "retention is the outcome of providing an experience so educationally beneficial and developmentally advantageous, that students will form favorable perception regarding the quality of their experience and decide to persist". Nora and Crisp (2007) suggest that mentoring programs aimed at providing experiences designed to assist student in adjusting to college life and becoming fully engaged in classroom and out-of-class activities should focus on providing support for the following elements: educational/career goal-setting and appraisal, emotional and psychological support, and academic subject knowledge support aimed at advancing a student's knowledge relevant to their chosen field.

Recently, the OUI has decided to focus attention towards the retention problem. The relatively low retention rate is an issue of great concern. There are several reasons which can explain the low retention rate. One of them being the fact that some students are not enrolled in a degree program, some of them take courses for enrichment and others in order to transfer credits to other universities. Another major reason for the low retention rate is due to the open admission policy and the fact that the OUI is a distance learning institution.

In an attempt to increase the retention rate, the OUl established a committee in order to identify the critical stages in which the dropout rate is high. It was found that one of these stages is the first course in which the student is enrolled. Following that, the committee decided to embark on a Retention Project whose aim is to help the new students overcome the hardships of the first course. The goals of the project are to guide, support, coach and accompany new students in their first semester at the OUI.

The Retention Project was designed as a pilot project which would span over three semesters, starting in the spring semester of 2007. The three semesters are accompanied by research aimed at evaluating the effectiveness of die project. We selected three introductory courses with a large population of students and an average dropout rate of $50 \%$. The courses were: "Introduction to Microeconomics", "Introduction to Statistics for Student of Social Sciences I" and "Introduction to Psychology". All the new students in these courses were sent an electronic letter inviting them to participate in the Retention Project. The students were offered to be paired up with a senior student who would accompany and coach them throughout their first semester at the OUI. The coaching philosophy includes the following three elements:

- University socialization such as acquaintance with the learning materials, the course website and the university administration.

- Academic support including self study skills and assistance with the course material.

- Continuous contact between the coach and the new student throughout the semester.

The framework of the project required that the coach and the new student will have a weekly meeting which will last an hour and a half. The time and place of the meeting will he set 
according to their convenience. The meetings could be either face to face or via technological means such as Telephone, Skype, Messenger etc.

The coaches were selected among students who have completed at least five courses at the OUI with an average grade of at least 80 and a grade of 80 or above in the relevant courses. They were required to participate in a training program which consisted of two four hourly sessions. The coaches received an appreciation diploma and a partial scholarship according to the number of actual coaching hours that took place.

The Retention Project has a website which includes a discussion group for the coaches, supplementary course materials for the coaches, and an electronic form used for reporting the coaching details. In addition the website includes video clips of coaches relating their experiences, dilemmas, success stories and their recommendations for ways of working with the students in order to achieve best results. Following the first semester, we conducted research in order to evaluate the success of the project. The research questions were:

1. Is there a difference between the coached students and the non coached students concerning their performance in the course?

2. Is there a difference between the coached students and the non coached students concerning their retention in the OUI?

3. Being a distance learning environment, what were the major used for coaching?

\section{METHODS}

The research population was composed of new students enrolled in the spring semester of 2007 in the following course: "Introduction to Microeconomics", "Introduction to Statistic for Students of Social Sciences I", and "Introduction to Psychology". All of the 1348 new students in these courses were sent an electronic letter inviting them to participate in the Retention Project. 201 students signed up to the Retention Project and each of them was paired up with a coach. The rest of the new students in these courses (1183) did not sign up to the project and did not receive coaching. Table 1 presents the distribution of the two groups of students among the three selected courses:

Table 1: Distribution of new students among the three courses

\begin{tabular}{lcc}
\hline \multicolumn{1}{c}{ Courses } & Number of Coached Students & Number of Non Coached Students \\
\hline Introduction of Microeconomic & 86 & 505 \\
Introduction to Statistic for Students of & 63 & 455 \\
Social Sciences course I & 52 & 223 \\
Introduction to Psychology & 201 & 1183 \\
\hline Total & & \\
\hline
\end{tabular}

The 201 coached students were distributed among 88 coaches. The number of student per coach's ranged from 1 to 4 , according to the coach's willingness to commit to the project.

The research instrument was the data regarding the assignments, the final exam and the students' course registration for the following semester. Alt of this data was available from the university information system. In addition both the coaches and the coached students reported 
their activities an electronic form submitted through the website. The data from these forms was used to analyze the means of communication.

\section{RESULTS AND DISCUSSION}

\section{Course Performance}

The requirements for passing a course at the $\mathrm{OUI}$ include handing in mandatory assignments and passing the final exam with a minimum grade of 60 (out of 100). The final grade in each course is computed as a weighted average between the grade in the final exam and the grades in the assignment. Each course defines the exact percentage of the assignments in the final grade, usually ranging from $15 \%$ to $30 \%$. In order to analyze the performance of the coached students in each of three courses, we looked at the following statistics both for the coached and non-coached students: the percentage of students who handed in all the required assignments, the assignments average grade, the percentage of students who took the final exam, the average exam grade and the final grade in the course.

\section{Course Assignments}

We checked if there is a difference between the coached students and the non-coached students concerning their performance in the course assignment. We looked both at the percentage of students who handed in all the required assignment and at the average grades (on a scale from 0 to 100) they received in these assignments.

Figure 1 presents for each course, the percentage of students in the coached and noncoached groups who handed in all the required assignments.

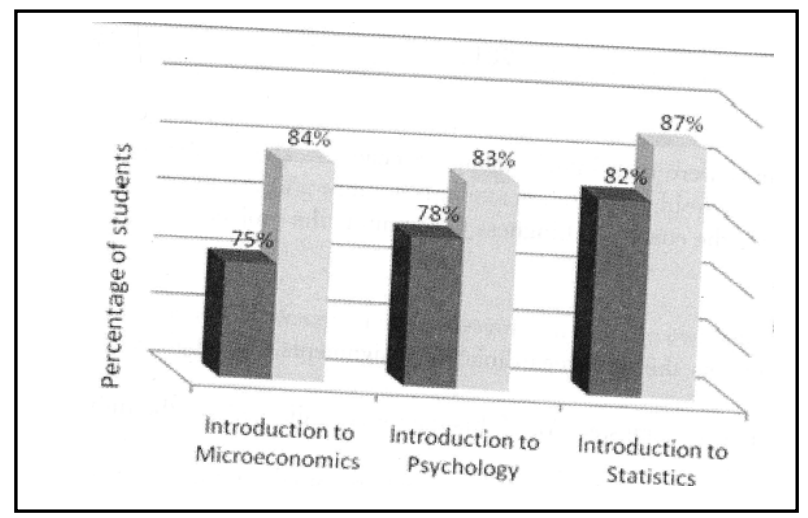

Figure 1. Percentage of students in the coached and non-coached groups handed in assignments

From figure 1, one can see that it all the courses the percentage of students who handed in all the required assignments was higher (although not significantly higher) for the coached students than for the non-coached students.

Figure 2 present for each course, the assignment average grade of the students in the coached and non-coached groups. 


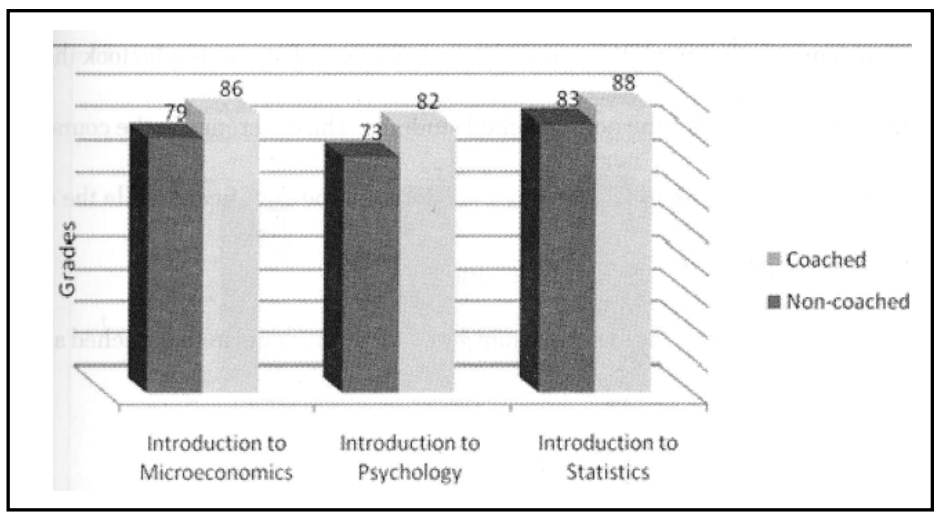

Figure 2. Assignment average grade of coached and non coached group of students

From figure 2, one can see that it all the courses the assignment average grade was higher for the coach students than for the non-coached students. The difference in all the three courses was found to be significant.

\section{Final Exam}

We checked if there is a difference between the coached students and the non-coached students concerning their performance in the final exam. We looked both at the percentage of students who took the final exam and at the average grades (on a scale from 0 to 100) they received in final exam.

Figure 3 presents for each course, the percentage of students in the coached and non-coach groups who took the final exam.

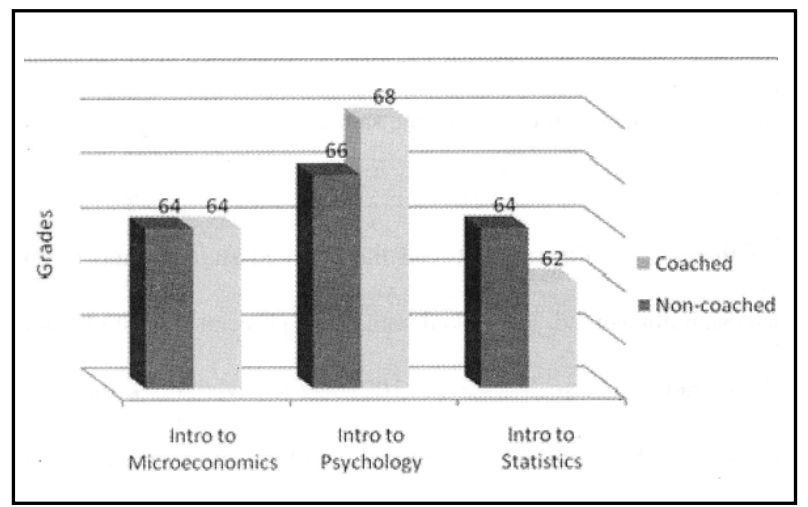

Figure 3. Percentage of students who took final exam

From figure 3 , one can see that in all the courses the percentage of students who took the final exam was higher for the coached than for the non-coached students. The difference in the course "Introduction to Microeconomics" and "Introduction to Psychology" was found to be significant while the difference in the course "Introduction to Statistic" was found to be not significant. 
Figure 4 presents for each course, the average exam grade of the students in the coached and non-coached groups.

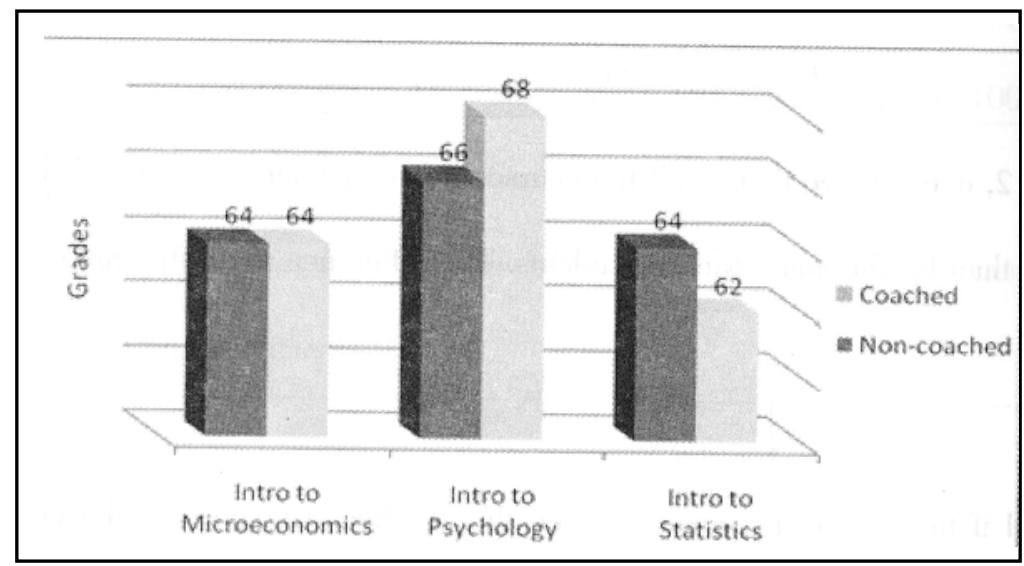

Figure 4. Average exam grade of students

Form figure 4, one can see that in two of the course ("Introduction to Psychology" and "Introduction to Statistic") the exam average grade was higher (although no significantly higher) for the coached students than for the non-coached students. In the course "Introduction to Economics" the average exam grade for coached and non-coached students was the same.

\section{Success in the Course}

We checked if there is a difference between to coached students and the non-coached students concerning their success in the course. We looked both at the percentage of students who passed the course and at the average final grades (on a scale from 0 to 100) they received in the course.

Figure 5 presents for each course, the percentage of students in the coached and noncoached groups who passed the course.

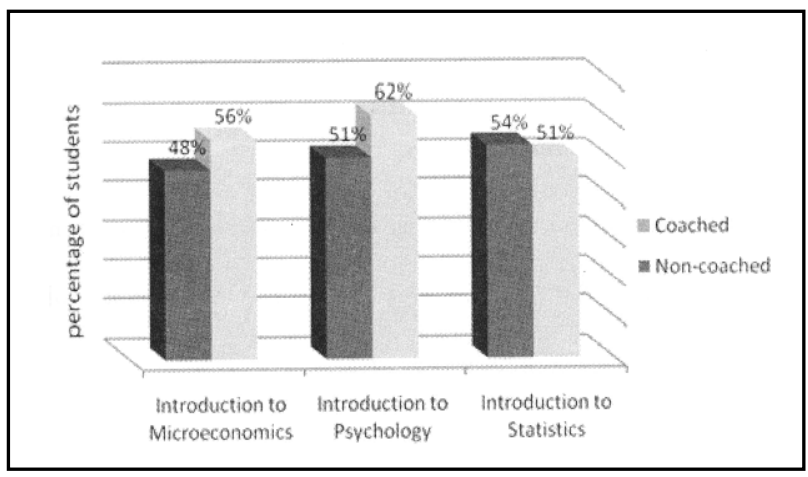

Figure 5. Percentage of students passed the course 
From figure 5, one can see that in two of the courses ("Introduction to Economic" and "Introduction to Psychology"), the percentage of student who passed the course was higher for the coached students than for the non-cached students. This difference was found to be significant. On the other hand in the course "Introduction to Statistics" the percentage of noncoached students who passed the course was significantly higher. The reason for the low percentages of students who passed the courses is due to the open admission policy and the fact that the students are allowed to take the exam in the following semester.

Figure 6 presents for each course, the average final grade of the students in the coached and non-coached groups.

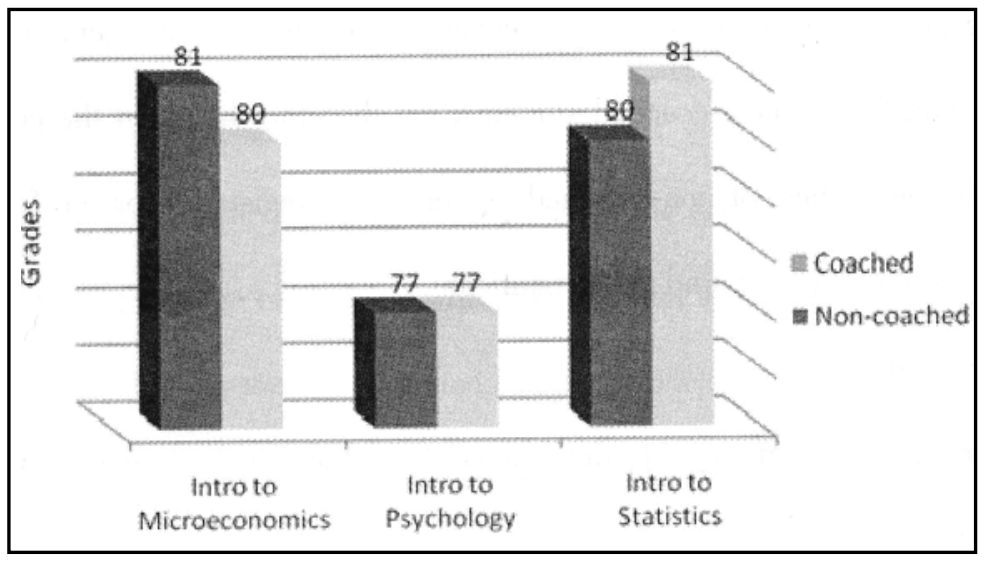

Figure 6. Average final grade of students

From Figure 6, one can see that there is no significant difference between the average final grades for the coached students and for the non-coached students in all three courses.

\section{Retention}

The retention can be measured by the percentage of students who registered to the following semester. We found that $65 \%$ of the coached students registered for the following semester, whole only $61 \%$ of the non-coached students registered to the following semester.

Figure 7 presents for each course, the percentage of students in the coached and noncoached groups who registered for the following semester. 


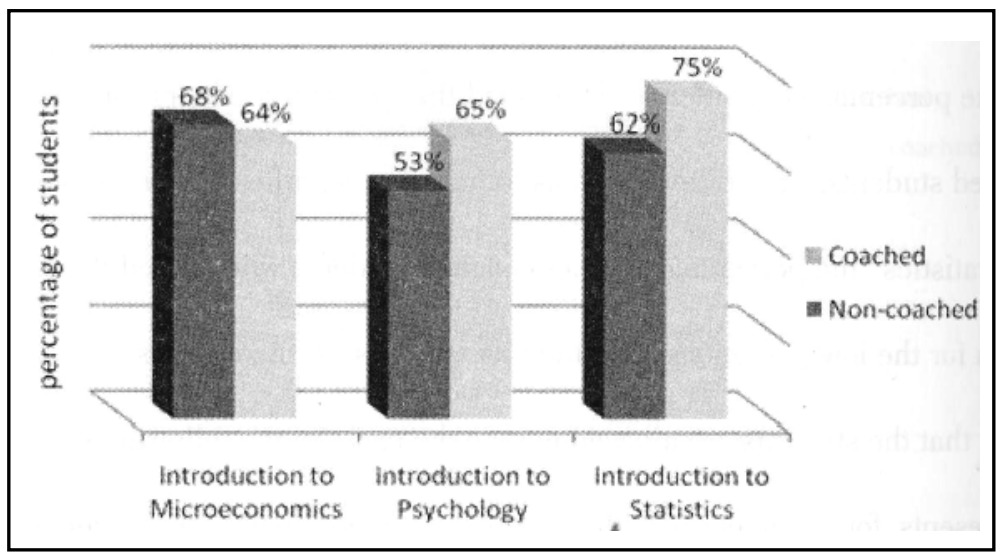

Figure 7. Percentage of students registered for the following semester

From Figure 7, one can see that in two of the courses ("Introduction to Psychology" and "Introduction to Statistic"), the percentage of students who registered for the following semester was higher for the coached students than for the non-coached student. On the other hand, in the course "Introduction to Microeconomic" the percentage of non-coached students who registered for the following semester was higher. All these differences were found to be significant.

\section{Means of Communication}

The means of communications was determined from the coaches' reports which were submitted through the project website. From analyzing these reports we found that $68 \%$ of the meetings between coaches and coached students were face-to-face meetings, $26 \%$ of the meetings were carried out by telephone, $3 \%$ by e-mail and $3 \%$ took place through the Internet using Skype, Messenger and ICQ.

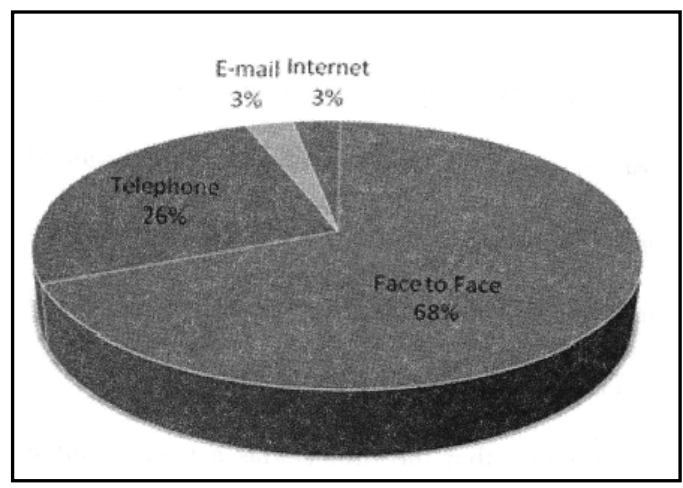

Figure 8. Means of students communication

From Figure 8 , one can see that $32 \%$ of the meetings were carried out using distance means of communications (telephone, e-mail and Internet). The high percentage of electronic meetings is due to the distance mode of education practiced at the OUI. 
About half of the face-to-face meetings took place at coaches' homes, $28 \%$ of the meeting took place at the coached students' homes, $16 \%$ took place at the study centers and $10 \%$ took place in other places.

\section{CONCLUSION}

In this paper we have described the Retention Project which is now running in its third semester. We described the project and presented some results from the first semester of its operation. The statistics concerning the course performance and retention were given separately for each of the three courses participating in the project. To summarize, we will present unified findings for the three courses:

- In all the courses the percentage of students who handed in all the required assignments was significantly higher for the coached students (85\%) than for non-coached students (79\%).

- In all the courses the percentage of students who took the final exam was significantly higher for the coached students $(79 \%)$ than for the non-coached students $(73 \%)$.

- In all the courses the percentage of students who passed the course was significantly higher for the coached students $(56 \%)$ than for the non-coached students $(52 \%)$. The percentage of students who failed the course was significantly lower for the coached students (22\%) than for the non-coached student; $(27 \%)$. The rest of the students still have an option to lake the exam in the following semester.

- In all the courses the percentage of students who registered fm the following semester was significantly higher for the coached students $(65 \%)$ than for the non-coached student (61\%).

- More than half $(68 \%)$ of the meetings between coaches and coached students were faceto-face meetings. The reset of the meetings (32\%) were carried out using distance means of communications such as: telephone, e-mail and Internet. The high percentage of electronic meetings is due to the distance mode of education practiced at the OUI.

From these findings it is apparent that the project has a positive affect on students' retention. The project is currently continuing in its third semester. We plan to analyze the students' performance and retention at the end of this semester in order to decide on the future of the project.

\section{REFERENCES}

Benaya, T. \& Zur, E. (2007). Website usage in a computer science course given in a distance learning environment. European Journal of Open, Distance, and E-learning, 2007/l.

Benaya, T., Lerner, A., \& Zur, E., (2007). Graduate studies - A second chance. Asian Journal of Distance Education, 5 (1), 4-19.

Gal-Ezer, J. \& Lupo, D. (2002). Integrating internet tools into traditional CS distance education: Students' attitudes. Computers \& Education 38 (4), 319-329.

Guri-Rosenblit, S. (1999). Distance and campus universities: Tensions and interactions. A comparative study of five countries. Pergamon.

Martinez, P. (1997). Improving student retention: A guide to successful strategies. London: Further Education Development Agency. 
Nora, A. \& Crips, G. (2007). Mentoring students: Conceptualization and validating the multidimensions of a support system. Journal of College Student Retention, 9 (3), 337-357, 2007/2008.

Peterson, S., Kovel-Jarboe, P., \& Schwartz, S. (1997). Quality improvement in higher education: Implications for student retention. Quality in Higher Education, 3 (2), 131141.

Tresman, S. (2001). Learning Journey and Student Retention in Programmes of Open Distance Education: A case study from the Open University UK. Proceeding of the $20^{\text {th }}$ World Conference on Open Learning and Distance Education: The Future of Learning - Learning for the Future: Shaping the Transition. Dusseldorf Germany.

Tresman, S. (2002). Toward a strategy for improved student retention in programmes of open, distance education: A case study from the open university UK. International Review of Research in Open and Distance Learning, 3 (1), 1-11. 